\title{
miR-223-3p suppresses inflammation to protect cardiomyocytes by targeting NLRP3 in acute myocardial infarction patients
}

\author{
Fangfang WANG ${ }^{1}$, Xin $\mathrm{CHEN}^{1}$, Ying $\mathrm{SONG}^{1}$, Shenglan $\mathrm{HUANG}^{1}$, Changle ZHOU ${ }^{1}$, Changgen $\mathrm{HUANG}^{1}$, \\ Zengguang $\mathrm{CHEN}^{1}$, Liangfeng $\mathrm{ZHANG}^{1}$, Yuan $\mathrm{JI}^{1 \star}$ (1)
}

\begin{abstract}
microRNA (miRNA) had been found played an important role in occurrence and development of acute myocardial infarction (AMI) disease. In this paper, we found that the circulating miR-223-3p in AMI patients was significantly higher than that in unstable angina (UA) patients and healthy people. Univariate and logistic regression analysis showed the circulating miR-223$3 p$ was a protective factor in the occurrence of AMI. We also found that the circulating miR-223-3p was negatively correlated with the serum CK-MB, cTnI, AST, LDH, TNF- $\alpha$, IL-6, IL-1 $\beta$ and IL-8. The luciferase reporter gene system confirmed that miR-223-3p targeted inhibition of NLRP3 expression in THP-1 and human peripheral blood mononuclear cell (PBMC), and miR-223-3p was negatively correlated with the expression of NLRP3 in the PBMC of AMI patients. In PBMC of healthy people, miR-146a-mimic could increase the expression of NLRP3, but decreased the level of TNF- $\alpha$ secretion. Moreover, H2C9 cells apoptosis by TNF- $\alpha$ in a dose-dependent. In conclusion, these results suggested that miR-223-3p suppressed inflammation to protect cardiomyocytes by targeting NLRP3 in AMI patients.
\end{abstract}

Keywords: miR-223-3p; NLRP3; acute myocardial infarction; inflammation.

Practical Application: Suppression of inflammation by miR-223-3p to protect cardiomyocytes through NLRP3 in AMI patients.

\section{Introduction}

Acute myocardial infarction (AMI) is an ischemic heart disease that is caused by acute and persistent ischemia/hypoxia of the coronary arteries. When myocardial infarction occurred, the cardiomyocytes caused irreversible damage and necrosis due to hypoxia and decreased supply of ATP (Boersma et al., 2003; Reed et al., 2017). The necrotic cells activate $d$ the autoimmune system and released a severe inflammatory response after releasing their contents. On the one hand, the release of inflammatory mediators initiated the repair of damaged tissues by the body (Michaels et al, 2000; Maier et al., 2005). On the other hand, inflammatory cytokines could induce cardiomyocyte apoptosis, and cardiomyocyte apoptosis further promoted the increase of inflammatory cytokines, which was one of the main causes of AMI progression (Pop et al., 2014; Westman et al., 2016). Therefore, anti-inflammatory treatment was an important part of the treatment of patients with AMI (Ong et al., 2018).

microRNA is a small non-coding RNA that plays an important role in regulating the transcription of genes. Previous studies had found that miRNAs participated in cardiomy--ocyte development, proliferation, apoptosis and other processes (Bang et al., 2014; Lu et al., 2010), and could be used as a new biomarker, playing an important role in the early diagnosis, prognosis (Wang et al., 2010; Yang et al., 2017), and even treatment of acute myocardial infarction. More and more research have showed that miRNAs were involved in the regulation of inflammatory response in AMI patients (Hristov \& Weber, 2015; Yang et al., 2015a). In animal experiments, miR-223-3p had been found as a novel MicroRNA Regulator of expression of voltage-gated $\mathrm{K}+$ channel Kv4.2 in acute myocardial infarction (Liu et al., 2016). And lots of previous researches had shown that miR-223-3p could inhibit inflammation in patients with various diseases by targeting inhibition of NLRP3 expression, such as acute lung injury (Feng et al., 2017), intestinal inflammation (Neudecker et al., 2017) and others (Haneklaus et al., 2012; Bauernfeind et al., 2012).

However, the regulatory mechanism of miR-223-3p on circulating inflammation in patients with AMI is unknown. In this study, we detected the expression of miR-223-3p by Real-time quantitative PCR, and found that miR-223-3p was not only up-regulated in the circulating of AMI patients, but also was associated with myocardial injury and inflammation in AMI patients. In vitro experiments shown that miR-223-3p suppressed inflammation to protect cardiomyocytes by targeting NLRP3 in peripheral blood mononuclear cells. All in all, this paper provide a new idea for AMI anti-inflammatory treatment.

\section{Materials and methods}

\subsection{Patients and blood sample}

53 cases AMI people which were diagnosed according to WHO standards for AMI (Mendis et al., 2011) and 53 cases UA patients which were diagnosed according to ACC/AHA 2007 guidelines (Anderson et al., 2007) were randomly included in this study, 
and their blood samples were collected within 12 hours after the onset of chest pain. At the same time, there were 53 healthy people who were accepted a medical examination. In addition, 10 cases healthy volunteers donated their blood for this study.

The present study was performed with the approval of the Ethics Committee of the Changzhou No.2 People' s Hospital, Affiliated Nanjing Medical University. All aspects of the study complied with the Declaration of Helsink. (Cook et al., 2003) In addition, all participants signed the informed consent.

\subsection{Serological clinical testing}

Serum was separated from blood samples after entrifuging $(1000 \times \mathrm{g})$ for ten minutes (5810R, Eppendorf AG, Germany). Automatic biochemical analyzer (AU680, Beckman Coulter, Inc., Brea, CA, USA) was used to detect the serum content of creatine kinase $\mathrm{MB}(\mathrm{CK}-\mathrm{MB})$, cardiac troponin I (cTnI), aspartate aminotransferase (AST), lactate dehydrogenase (LDH), and commercial elisa kit (Shanghai Kang Lang biology, China). was used to detect the serum content of TNF- $\alpha$, IL-6, IL-1 $\beta$ and IL- 8 .

\subsection{Real-time quantitative PCR}

Real-time quantitative PCR (RT-qPCR) was used to detect the expression of miRNA and mRNA. Total RNA was isolated by QIAzol lysis reagent (QIGEN, Germany) in the serum and isolated by trizol (taraka, Japan) in cells. And then One Step PrimeScript miRNA cDNA Synthesis Kit (Takara, Japan) was used to synthesize cDNA. PCR parameters set: $37^{\circ} \mathrm{C} / 60$ minutes, $85^{\circ} \mathrm{C} / 5$ seconds.

20 ul RT-qPCR system was prepared with SYBR Premix Ex TaqTM II (TakaRa, Japan), and ABI 7500 Fluorescence Quantitative PCR Instrument (Applied Biosystems, USA) was used to expand. U6 was chosen as internal reference for miRNA, and GAPDH for mRNA. RT-qPCR parameters set: $95^{\circ} \mathrm{C} / 30 \mathrm{~s}$, $\left[90^{\circ} \mathrm{C} / 5 \mathrm{~s}, 65^{\circ} \mathrm{C} / 30 \mathrm{~s}\right]-40$ cycles. RT-qPCR primers, miR-223-3p-F: 5'-ACACTCCAGCTGGGTGTCAGTTTGTCAAAT-3'; miR-223-3p-R:5'-TGGTGTCGTGGAGTCG-3'; NLRP3-F: 5'-GATCTTCGCTGCGATCAACAG-3'; NLRP3-R: 5'-CGTGCATTATCTGAACCCCAC-3'.

\subsection{Cell and cell transfection}

THP-1 cells (TIB-202, ATCC, USA) was cultured with RPMI-1640 medium (R8758, sigma-Aldrich, USA) which was plused $10 \%$ fetal bovine serum (10099-141, Gbico, USA). H9C2 cells (CRL-1446, ATCC, USA) was cultured with DMEM medium (12491-15, ThermoFisher, USA). $37^{\circ} \mathrm{C}$ and $5 \% \mathrm{CO}_{2}$ was the culture environment for all cells.

miR-223-3p-NC (5'-AGAUCCAGCCAGGCGAUAUAUGU-3'), miR-223-3p-mimic (5'-UGUCAGUUUGUCAAAUACCCCA-3') and miR-223-3p-inhabitor (5'-ACAGUCAAACAG

UUUAUGGGGU-3') were designed and synthesized by Shenggong Bioengineering Co., Ltd. (ShangHai, China), and were directly transferred into cells by Lipofectamine ${ }^{\mathrm{TM}} 2000$ transfection reagent (11668019, Invitrogen, CA, USA). For wild type or mutation mRNA 3'-UTR of SNLRP3, they were first connected to pisCHECK2 (Promega, WI, USA) and then being transfected into cells as miRNA.

\subsection{Western blot}

RIPA lysate buffer (P0013C, Beyotime, Shanghai, China) was used to extract total cellular protein, and BCA kit (P0009, Beyotime, Shanghai, China) was used to determine protein concentration. Then cell lysates were separated by SDS-page and transferred to PVDF membrane. Primary antibody was selected as follows: anti-NLRP3 (ab214185,1:1000, ABCAM, Cambs, UK), or anti-GAPDH (ab9485,1:3000, ABCAM, Cambs, UK). And second antibody was selected as follows: goat anti-rabbit (ab150077, 1:1000, ABCAM, Cambs, UK). Primary antibody was incubated overnight at $4{ }^{\circ} \mathrm{C}$ and second antibody was incubated for 1 hour at room temperature.

\subsection{Cell apoptosis assay}

24 hours after inducing by different dose of IL-1 $\beta$ (CYT-708, AmyJet Scientific, WuHan, China), H9C2 cells were collected, and the Annexin V FITC/PI kit (Invitrogen, USA) was used for flow cytometry to detect apoptosis. Beckman CytoFLEX Flow cytometry (BECKMAN, USA) was used to analysis the apoptosis of cells.

\subsection{Statistical analysis}

Data was presented in (mean \pm standard deviation) and analyzed by SPSS 25.0. Student's t-test or chi-square test was used to compare differences between two groups. One-way ANOVA with Duncan's post-hoc test was used for comparing multiple groups. The correlation between serum level of miR-223-3p and inflammatory factors / myocardial enzyme in patients with AMI was analyzed by Pearson's correlation coefficient. Logistic regression models were constructed to determine the odds ratio (OR) and 95\% confidence interval (CI) for putative risk factors associated with AMI. $\mathrm{P}<0.05$ was considered to indicate a statistically significant difference.

\section{Results}

\section{$3.1 \mathrm{miR}-223-3 p$ was up-regulated in the circulating of AMI patients}

The expression of miR-223-3p in the serum or PBMC of healthy people $(n=53)$, UA patients $(n=53)$ and AMI patients $(\mathrm{n}=53$ ) were measured by RT-qPCR, and results showed that the serum or PBMC level of miR-223-3p in the AMI patients was significantly higher than that in UA group $(\mathrm{P}<0.001)$, and that in control group was the lowest of three group (Figure 1).

\section{2 miR-223-3p was associated with the occurrence of AMI}

Univariate analysis showed that (Table 1) there were no significant differences in gender, age, smoking, hypertension, TC, TG, HDL-C and LDL-C between three group ( $\mathrm{P}>0.05)$. However, the serum CK-MB, cTnI, AST, LDH, TNF- $\alpha$, IL-6, IL- $1 \beta$ and IL- 8 in AMI patients was significantly higher than that in health people and UA patients $(\mathrm{P}<0.001)$.

In logistic regression, we made AMI $(1=$ yes, $0=$ no $)$ as the dependent variable, age, male $(0=$ female, $1=$ male $)$, 
A

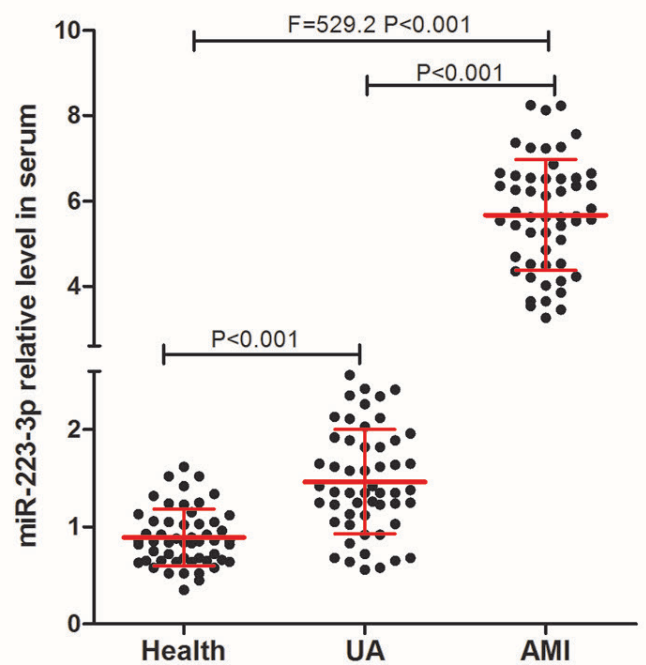

B

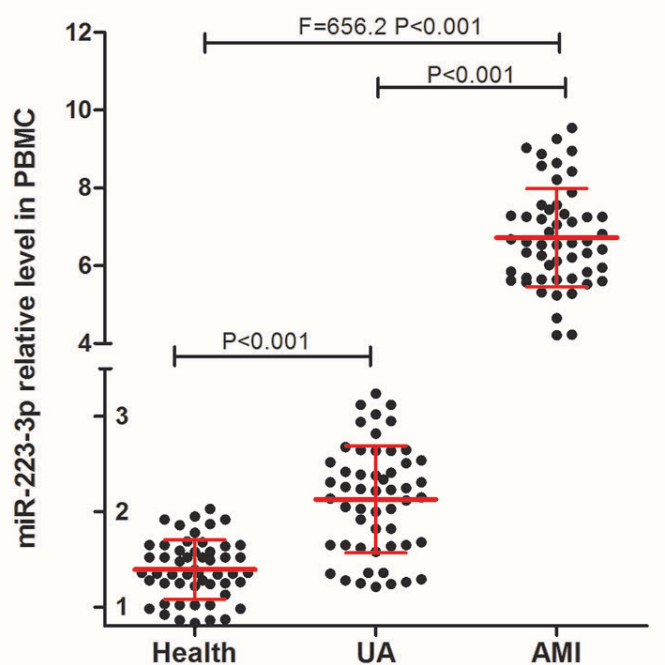

Figure 1. miR-223-3p expression in the circulating of AMI, UA and Health group. (A-B) miR-223-3p was high expression in the serum (A) or PBMC (B) of patients with AMI $(n=53)$ which was compared with health people $(n=53)$ or UA patients $(n=53)$.

Table 1. Comparison of clinical data of the three groups of study subjects.

\begin{tabular}{|c|c|c|c|c|}
\hline \multirow{2}{*}{ Variables } & \multicolumn{2}{|c|}{ No-AMI } & \multirow{2}{*}{ AMI } & \multirow{2}{*}{ Probability value } \\
\hline & Health & UA & & \\
\hline Number (cases) & 53 & 53 & 53 & not applicable \\
\hline Age (year) & $60.2 \pm 7.9$ & $59.6 \pm 9.0$ & $60.8 \pm 8.2$ & 0.674 \\
\hline male $(\mathrm{n} / \%)$ & $32 / 60.4$ & $36 / 67.9$ & $35 / 66.0$ & 0.623 \\
\hline Smoking (n/\%) & $27 / 50.9$ & $26 / 49.1$ & $29 / 54.7$ & 0.398 \\
\hline Hypertension (n/\%) & $20 / 37.7$ & $22 / 41.5$ & $21 / 39.6$ & 0.428 \\
\hline $\mathrm{TC}(\mathrm{mmol} / \mathrm{L})$ & $3.98 \pm 0.72$ & $4.08 \pm 0.93$ & $4.19 \pm 0.92$ & 0.366 \\
\hline $\mathrm{TG}(\mathrm{mmol} / \mathrm{L})$ & $1.45 \pm 0.83$ & $1.51 \pm 0.89$ & $1.53 \pm 1.06$ & 0.471 \\
\hline $\mathrm{HDL}-\mathrm{C}(\mathrm{mmol} / \mathrm{L})$ & $1.22 \pm 0.84$ & $1.19 \pm 0.92$ & $1.12 \pm 0.89$ & 0.209 \\
\hline LDL-C (mmol/L) & $2.35 \pm 0.92$ & $2.42 \pm 0.62$ & $2.52 \pm 0.67$ & 0.513 \\
\hline CK-MB (U/L) & $15.3 \pm 4.2$ & $15.5 \pm 6.8$ & $136.0 \pm 76.9$ & $<0.001$ \\
\hline cTnI (ug/L) & $0.12 \pm 0.06$ & $0.34 \pm 0.11$ & $54.9 \pm 28.6$ & $<0.001$ \\
\hline AST (U/L) & $30.9 \pm 3.9$ & $33.6 \pm 8.3$ & $69.8 \pm 14.7$ & $<0.001$ \\
\hline LDH (U/L) & $156.8 \pm 22.4$ & $165.1 \pm 36.4$ & $687.4 \pm 242.2$ & $<0.001$ \\
\hline TNF- $\alpha(n g / L)$ & $75.9 \pm 26.4$ & $142.3 \pm 80.2$ & $275.2 \pm 109.3$ & $<0.001$ \\
\hline IL-6 (ng/L) & $12.1 \pm 6.8$ & $35.2 \pm 19.3$ & $73.3 \pm 30.8$ & $<0.001$ \\
\hline IL-1 $\beta$ (ng/L) & $21.8 \pm 10.5$ & $46.9 \pm 25.1$ & $112.8 \pm 32.8$ & $<0.001$ \\
\hline IL-8 (ng/L) & $20.4 \pm 7.3$ & $45.3 \pm 19.2$ & $98.1 \pm 30.9$ & $<0.001$ \\
\hline
\end{tabular}

$\mathrm{TC}=$ total cholesterol, $\mathrm{TG}=$ triglycerides, $\mathrm{HDL}-\mathrm{C}=$ high-density cholesterol, $\mathrm{LDL}-\mathrm{C}=$ low density cholesterol, $\mathrm{AMI}=$ acute myocardial infarction, $\mathrm{UA}=$ unstable angina, $\mathrm{n}=$ number

hypertension $(0=$ no, 1 = yes $)$, smoking $(0=$ no, $1=$ Yes $)$, hyperlipidemia $(0=$ none, $1=$ yes $), T C, T G$, LDL-C, HDL-C, CK-MB, cTnI, AST, LDH, TNF- $\alpha$, IL- 6 , IL- $1 \beta$ and IL- 8 as independent variables. And we found that (Table 2) serum or PBMC miR-223-3p was a protective factor in the occurrence of AMI.

\section{3 miR-223-3p was associated with myocardial injury and inflammation in AMI}

To analyze the correlation between circulating miR-223-3p and myocardial injury-related enzymes in 53 cases AMI patients, and found that (Figure 2) the serum miR-223-3p was negatively correlated with serum CK-MB $(r=-0.567, \mathrm{P}<0.001)$, 
Table 2. Results of the logistic regression analysis.

\begin{tabular}{|c|c|c|c|c|c|c|}
\hline Variables & B & S.E. & Wald & Sig. & $\operatorname{Exp}(B)$ & $95 \%$ CI \\
\hline male (n/\%) & -0.895 & 0.610 & 1.752 & 0.171 & 2.402 & $0.615-9.063$ \\
\hline Hypertension (n/\%) & -0.166 & 0.341 & 0.143 & 0.235 & 0.706 & $0.236-2.215$ \\
\hline $\mathrm{TC}(\mathrm{mmol} / \mathrm{L})$ & 0.321 & 0.621 & 0.308 & 0.414 & 0.204 & $0.211-2.371$ \\
\hline $\mathrm{HDL}-\mathrm{C}(\mathrm{mmol} / \mathrm{L})$ & -0.107 & 0.148 & 0.508 & 0.439 & 1.037 & $0.945-1.139$ \\
\hline LDL-C (mmol/L) & 0.053 & 0.203 & 0.002 & 0.968 & 0.997 & $0.847-1.172$ \\
\hline CK-MB (U/L) & 0.162 & 0.784 & 0.139 & 0.130 & 0.754 & $0.187-3.076$ \\
\hline CTnI (ug/L) & 0.245 & 1.063 & 0.458 & 0.025 & 2.087 & $0.265-16.426$ \\
\hline IL-6 (ng/L) & 5.614 & 2.250 & 3.017 & 0.083 & 3.349 & $0.488-20.646$ \\
\hline IL-1 $\beta$ (ng/L) & 0.251 & 0.038 & 5.223 & 0.032 & 1.210 & $1.144-1.278$ \\
\hline IL-8 (ng/L) & 2.312 & 1.258 & 3.125 & 0.059 & 1.258 & $0.982-1.324$ \\
\hline PBMC miR-223-3p & -2.124 & 0.792 & 7.301 & 0.005 & 8.210 & $1.784-38.214$ \\
\hline Serum miR-223-3p & -1.592 & 0.625 & 5.012 & 0.008 & 9.236 & $2.354-26.371$ \\
\hline
\end{tabular}

$\mathrm{B}=$ regression coefficient, $\mathrm{S} . \mathrm{E} .=$ standard error, $\mathrm{CI}=$ confidence interval, $\mathrm{n}=$ number.

cTnI $(\mathrm{r}=-0.589, \mathrm{P}<0.001)$, AST $(\mathrm{r}=-0.316, \mathrm{P}=0.0213)$ and LDH $(r=-0.397, P=0.0033)$, and the PBMC miR-223-3p was negatively correlated with serum CK-MB $(\mathrm{r}=-0.544, \mathrm{P}<0.001)$, cTnI $(r=-0.489, \mathrm{P}=0.0002)$, AST $(r=-0.281, \mathrm{P}=0.0413)$ and $\mathrm{LDH}(\mathrm{r}=-0.381, \mathrm{P}=0.0049)$.

Furthermore, we also analyzed the correlation between circulating miR-223-3p and serum inflammatory factors in 53 cases AMI patients, and found that (Figure 3 ) the serum miR-223-3p was negatively correlated with serum TNF- $\alpha(r=-470, P=0.0004)$, IL-6 $(\mathrm{r}=-400, \mathrm{P}=0.003), \mathrm{IL}-1 \beta(\mathrm{r}=-0.553, \mathrm{P}<0.001)$ and IL-8 $(r=-0.268, P=0.0493)$, and the serum miR-223-3p was negatively correlated with serum TNF- $\alpha(\mathrm{r}=-0.419, \mathrm{P}=0,0018)$, IL-6 $(r=-0.448, P=0.0008)$, IL- $1 \beta(r=-0.522, P<0.001)$ and IL-8 $(r=-371, P=0.0063)$.

\section{4 miR-223-3p regulated inflammation by targeting NLRP3}

According to the bioinformatics website (Agarwal et al., 2015), we found that there was a complementary sequence to miR-223-3p at the 3'-UTR end of NLRP3 mRNA (Figure 4A). We validated the luciferase gene reporter system, and found that transfection of miR-223-3p-mimic significantly increased WT type 3'-UTR luciferase activity $(\mathrm{P}<0.001)$ in THP-1 cells, and miR-223-3p-inhabitor significantly decreased it, but not work in MUT (Figure 4B).

In addition, miR-223-3p was negatively correlated with NLRP3 mRNA in PBMC of 53 cases AMI patients $(r=-0.675$, $\mathrm{P}<0.001$ ) (Figure 4C). In PBMC of 10 cases healthy people, transferring miR-223-3p-mimic could inhibit the expression of NLRP3, and exactly the opposite with miR-223-3p-inhabitor
(Figure 4F and Figure 4G). More important was the change of TNF- $\alpha$ in culture for PBMC, as shown in Figure 4E, miR-223-3p could decrease the content of TNF- $\alpha$.

\subsection{Cardiomyocytes apoptosis by IL-1 $\beta$ in a dose-dependent}

We examined the effects of different concentrations of IL- $1 \beta$ on apoptosis of $\mathrm{H} 2 \mathrm{C} 9$ cells, and found that the apoptotic rate of $\mathrm{H} 2 \mathrm{C} 9$ cells increased with increasing TNF- $\alpha$ concentration (Figure 5).

\section{Discussion}

In this paper, we found that the circulating miR-223-3p in AMI patients was significantly higher than that in UA patients and healthy people. Moreover, univariate and logistic regression analysis showed the circulating miR-223-3p was a protective factor in the occurrence of AMI. Although there were no clinical data in published studies indicating that miR-223-3p was highly expressed in peripheral blood of patients with AMI, animal studies had shown that (Liu et al, 2016) upregulation of miR-223-3p in AMI repressed the expression of $\mathrm{KCND} 2 / \mathrm{Kv} 4.2$ resulting in reduction of Ito density that could cause APD prolongation and promote arrhythmias in AMI.

In addition, we also found that circulating miR-223-3p in AMI patients was negatively correlated with serum myocardial enzyme, such as CK-MB, cTnI, AST and LDH, and was negatively correlated with serum inflammatory cytokines, such as TNF- $\alpha$, IL-6, IL-1 $\beta$ and IL-8. Myocardial local and systemic inflammatory responses played an important role in the development of ventricular remodeling and heart failure after acute myocardial 

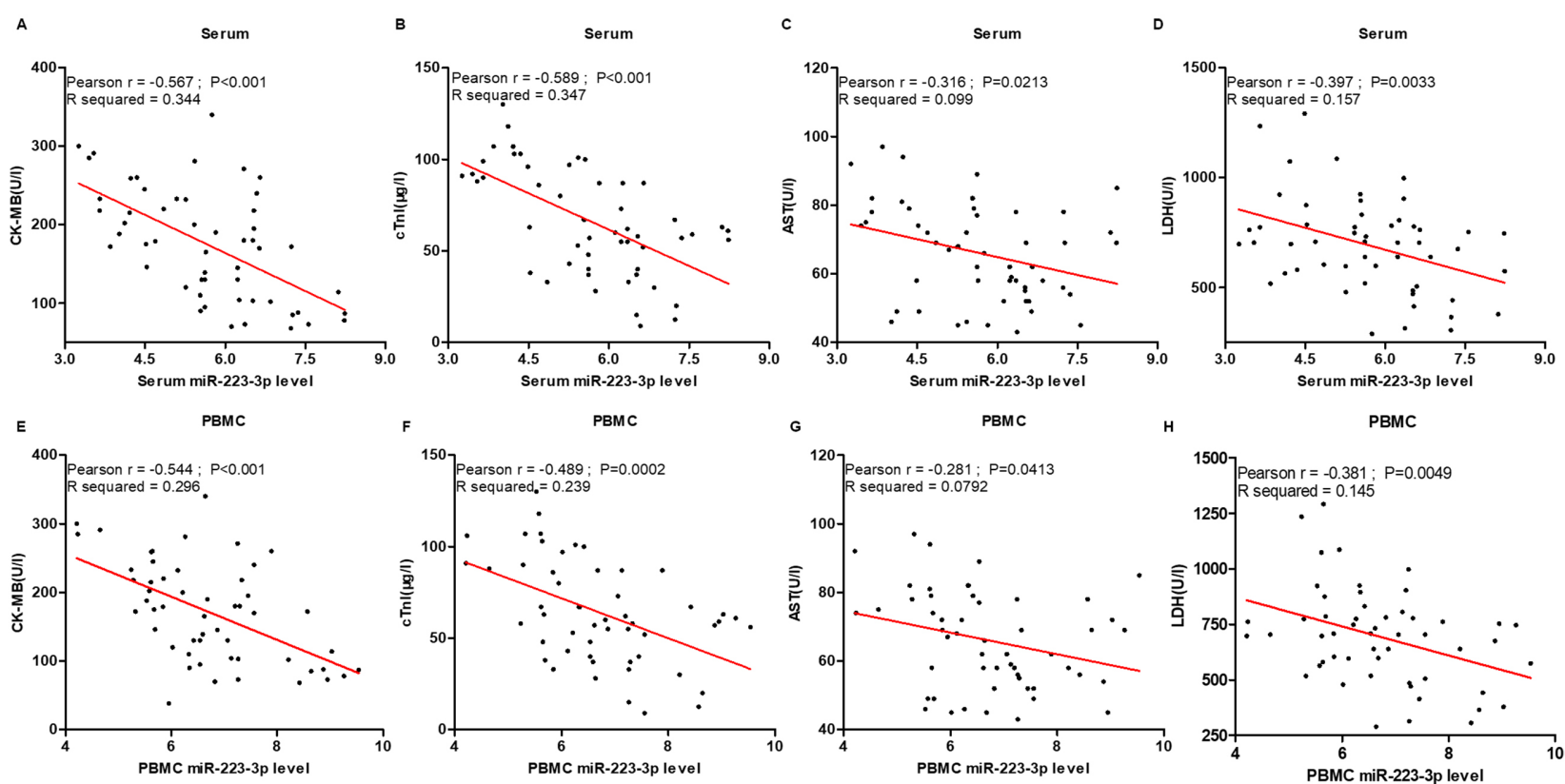

Figure 2. Circulating miR-223-3p was negatively correlated with serum myocardial enzyme in AMI. A-D, Serum miR-223-3p expression was negatively correlated with serum CK-MB (A), cTnI (B), AST (C) and LDH (D) levels in AMI patients; E-H, The expression of miR-223-3p in PBMC was negatively correlated with serum CK-MB (E), cTnI (F), AST (G) and LDH (H) levels in AMI patients.
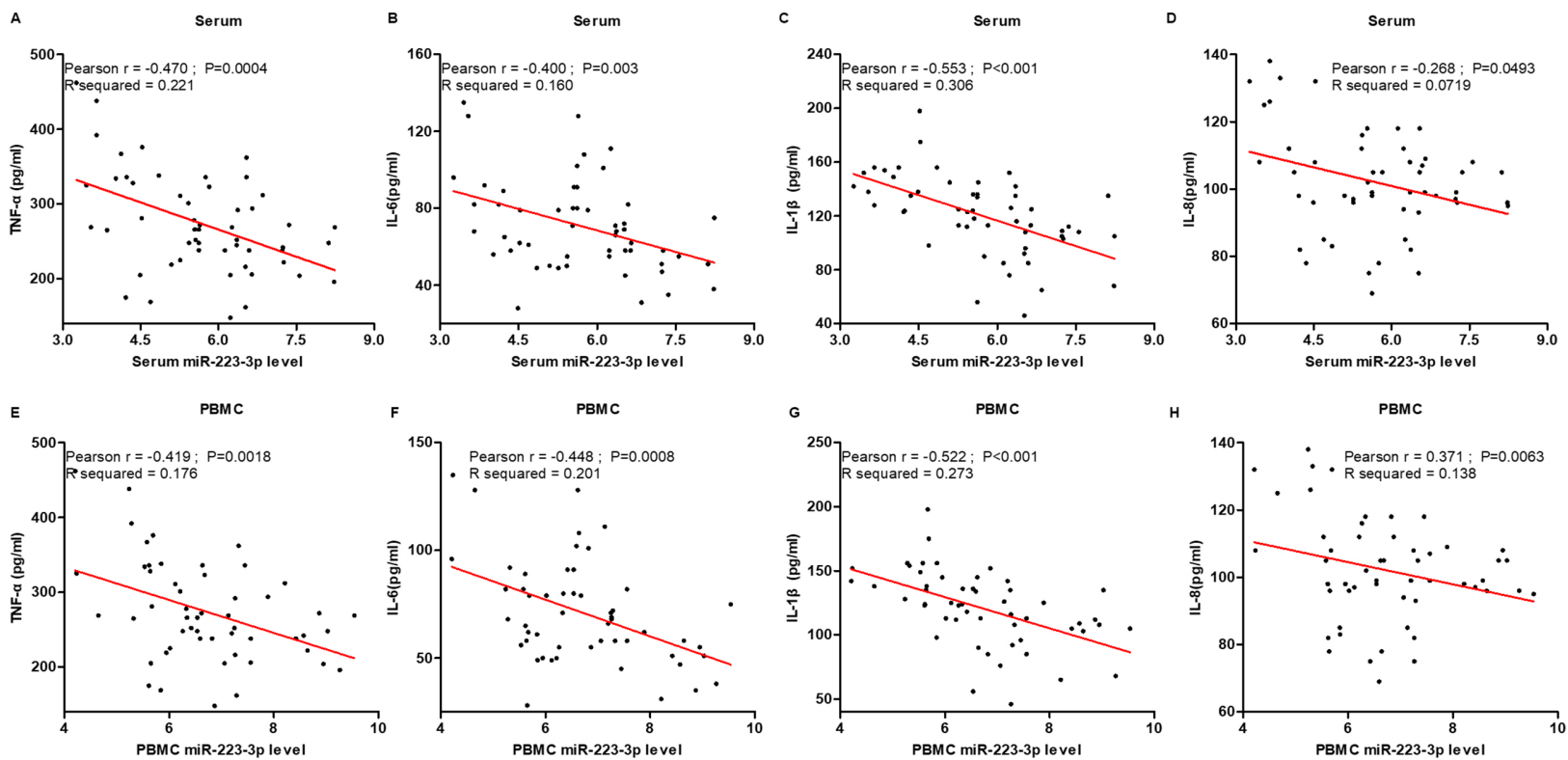

Figure 3. Circulating miR-223-3p was negatively correlated with serum inflammatory factor in AMI. A-D, Serum miR-223-3p expression was negatively correlated with serum TNF- $\alpha$ (A), IL-6 (B), IL-1 $\beta$ (C) and IL-8 (D) levels in AMI patients; E-H, The expression of miR-223-3p in PBMC was negatively correlated with serum TNF- $\alpha(\mathrm{E})$, IL-1 $\beta$ (F), IL-6 (G) and IL-8 (H) levels in AMI patients.

infarction. In AMI patients, myocardial injury came from two aspects. In addition to myocardial ischemic injury after AMI, immune-mediated inflammatory response also played a role in aggravating myocardial damage and expanding myocardial infarction. Necrotic myocardial tissue after AMI caused complement activation, cytokine release, inflammation, and chemotaxis and infiltration of immune cells, as well as myocardial damage through pathological autoimmune responses (Frangogiannis et al., 2002). Cytokines, such as TNF- $\alpha$, IL-6, IL-1 $\beta$ and IL-8, were polypeptides secreted by various cells such as lymphocytes, monocytes, macrophages, and vascular endothelial cells. They were released into the blood during the inflammatory reaction, and their 

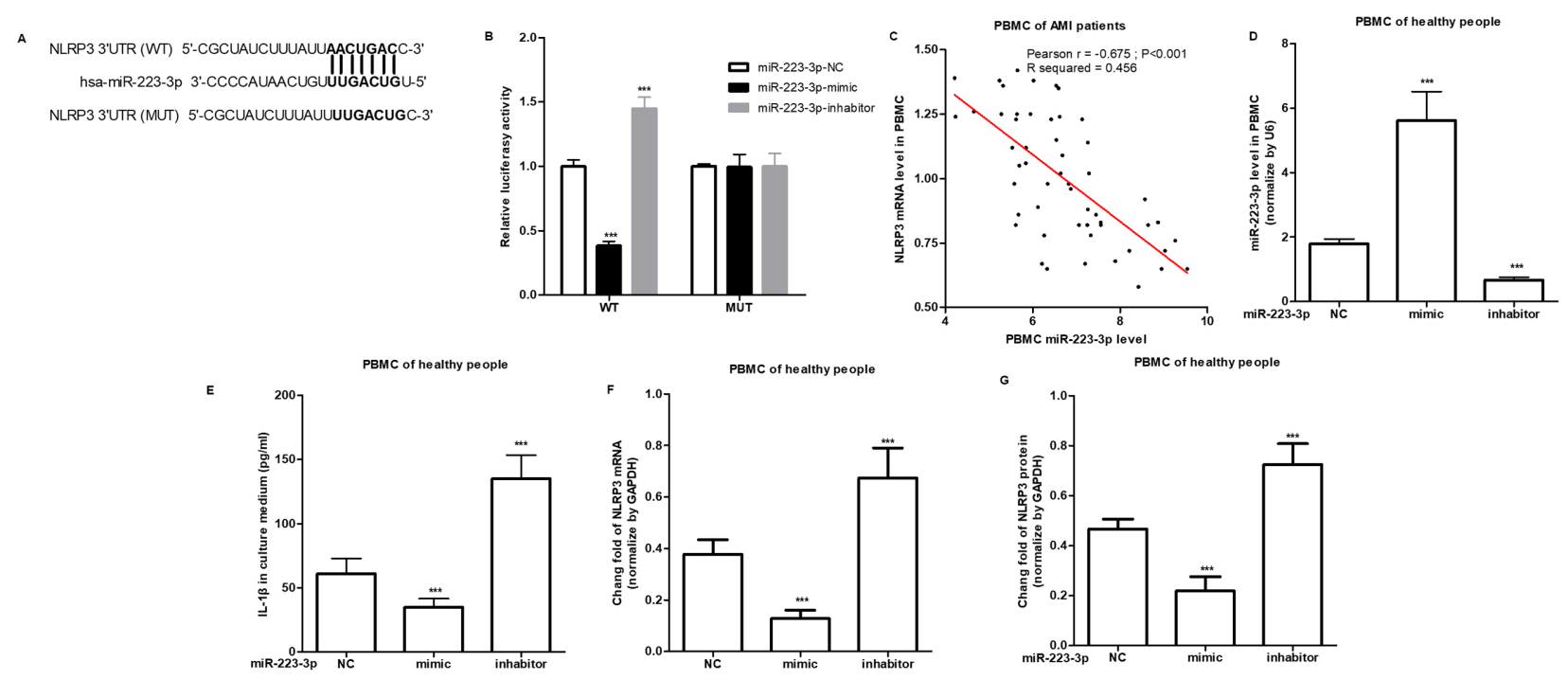

Figure 4. miR-223-3p regulated inflammation in PBMC by targeting NLRP3. (A) Sequence in which NLRP3 and miR-223 are combined; (B) miR-223-3p-NC/miR-223-3p-mimic/miR-223-3p-inhabitor were transected into THP-1 cells, and luciferase activity was detected (Perform 3 independent replicate experiments); (C) miR-223-3p was negatively correlated with NLRP3 mRNA in PBMC of AMI patients (n = 53); (D) RT-qPCR was used to detect the expression of miR-223-3p in PBMC of healthy people $(n=10)$; (E) The content of IL- $1 \beta$ in culture medium for PBMC of 10 cases healthy people; (F) RT-qPCR was used to detect the expression of NLRP3 mRNA in PBMC of healthy people ( $\mathrm{n}=10)($ Perform 3 independent replicate experiments); $(\mathrm{G})$ Western blot was used to detect the expression of NLRP3 mRNA in PBMC of healthy people ( $\mathrm{n}=10$ ) (Perform 3 independent replicate experiments). Compared with miR-223-3p-NC, ${ }^{* * *}$ was $\mathrm{P}<0.001$.
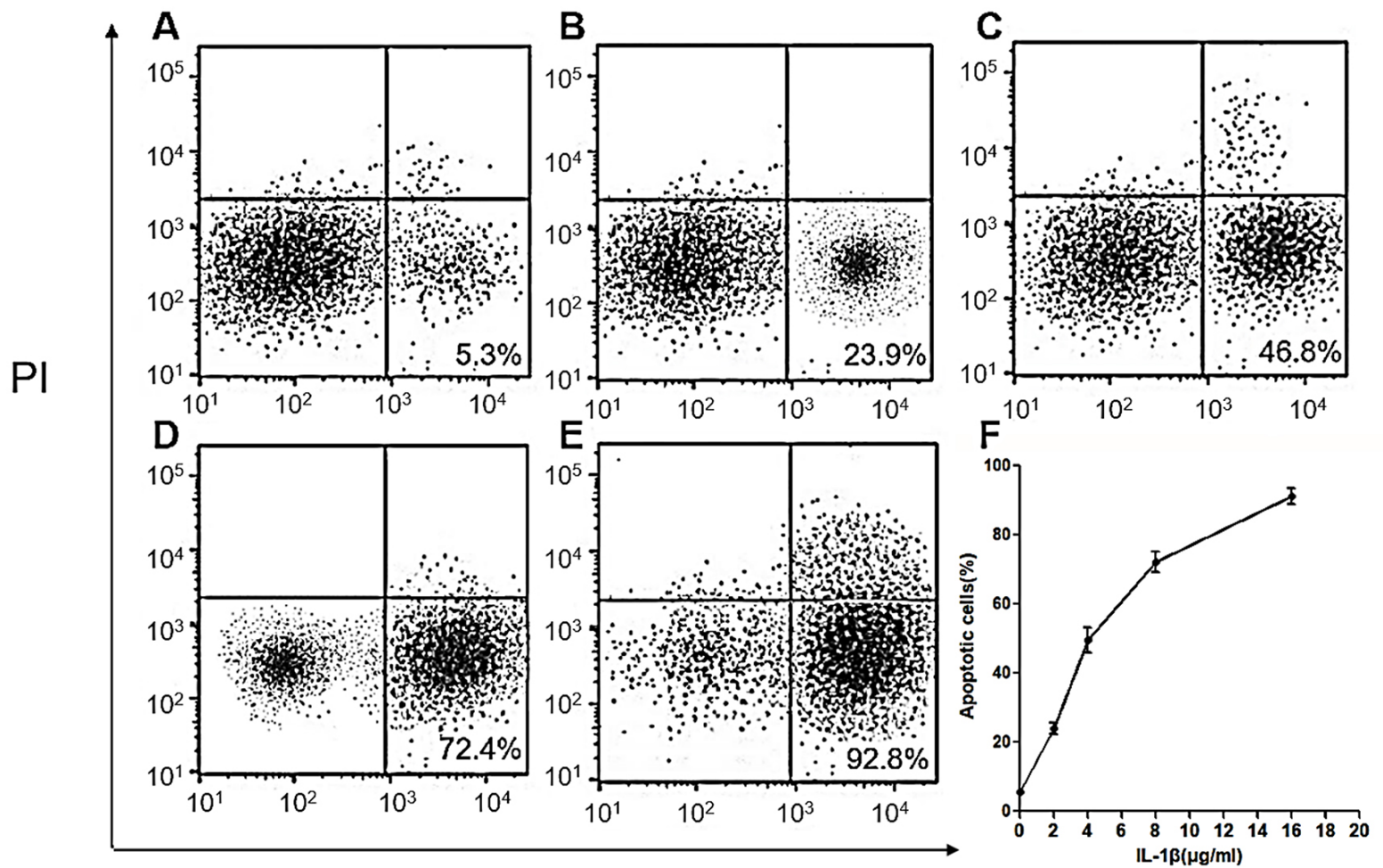

\section{Annexin V FITC}

Figure 5. IL-1 $\beta$ induced the apoptosis of cardiomyocytes in a dose-dependent. (A-E) Flow cytometry was used to detect the apoptosis of H9C2 cells with 0 (A), 2 (B), 4 (C), 8 (D) and 16 (E) ug/L IL-1 $\beta$; (F) Statistical analysis of apoptosis in H9C2 cells (3 independent repeats per experiment). 
concentration in the blood reflected the stage of inflammation of the body degree (Hartman et al., 2018).

miR-223-3p was located at the Xq12 position of human chromosome, and previous studies had shown that it could regulate inflammation in human body. Zhuang et al. (2012) found that miR-223-3p could affect obesity-related tissue inflammation by regulating macrophage activation. Neudecker et al. (2017) found that the bone marrow-derived miR-223-3p could regulated the seriousness of the human intestine. Moreover, miR-223-3p also played a role in regulating inflammation in organ damage (Feng et al., 2017; Yang et al., 2015b), infection and cancer (Haneklaus et al., 2013). Combined with our findings above, it suggested that miR-223-3p might also regulate peripheral blood inflammation in patients with AMI. It was well known that miRNAs were non-coding RNAs and must function by regulating target genes. For miR-223-3p, many studies had shown that miR-223-3p regulated inflammation by targeting NLRP3 expression (Bauernfeind et al., 2012). And the luciferase reporter gene system confirmed that miR-223-3p targeted inhibition of NLRP3 expression in THP-1 and human peripheral blood mononuclear cell in this study.

The NLRP3 inflammatory corpuscle was an important component of the pattern recognition receptor family in the innate immune system. Once activated, the NLRP3 inflammatory corpuscle would recruit and interact with the apoptosis-associated speck-like protein containing CARD, thereby recruiting and binding procaspase- 1 to activate its own cleavage and activation into caspase-1, maturing the IL-1 $\beta$ precursor (pro-IL-1 $\beta$ ) and IL-18 precursor (pro-IL-18) into active pro-inflammatory cytokines (IL-1 $\beta$ and IL-18), ultimately acting as a pro-inflammatory factor (Schroder et al., 2010; Zhou et al., 2011). The NLRP3 inflammatory body recognized different risk signals and induced a sterile inflammatory response, making it to be the best candidate for pattern recognition receptors that function in the AMI process. Mezzaroma et al. found that inhibited the activation of NLRP3 inflammatory bodies by siRNA or drugs could reduce cardiomyocyte apoptosis and ultimately reduce myocardial remodeling after myocardial infarction in permanent myocardial infarction model mice (Mezzaroma et al., 2011). Liu et al. (2014) detected an up-regulation of NLRP3 expression in the ischemic heart, increased caspase- 1 activity, and increased IL- $1 \beta$ and IL-18 in the C57BL/6J mouse myocardial ischemia-reperfusion model. And intramyocardial injection NLRP3 siRNA or intraperitoneal injection of NLRP3 inflammatory inhibitor BAY 11-7028 could reduce macrophage and neutrophil infiltration in myocardial ischemia-reperfusion injury, and reduce myocardial cell apoptosis and myocardial infarct size.

In this study, we found miR-223-3p-mimic could reduce the expression of NLRP3 and the secretion of IL-1 $\beta$ human $\mathrm{PBMC}$ in vitro. At the same time, IL- $1 \beta$ induced the apoptosis of cardiomyocytes in a dose-dependent in vitro. IL- $1 \beta$ was an important cytokine that played a pro-inflammatory role in the body and was also one of the two cytokines regulated by NLRP3 (Mulay et al., 2013; Mishra et al., 2013).

\section{Conclusion}

Circulating miR-223-3p was highly expressed in AMI patients and was negatively correlated with serum inflammatory factor / myocardial enzyme. More importantly was miR-223-3p suppressed circulating inflammation to protect cardiomyocytes by targeting NLRP3 in AMI patients.

\section{References}

Agarwal, V., Bell, G. W., Nam, J. W., \& Bartel, D. P. (2015). Predicting effective microRNA target sites in mammalian mRNAs. eLife, 4, e05005. http://dx.doi.org/10.7554/eLife.05005. PMid:26267216.

Anderson, J. L., Adams, C. D., Antman, E. M., Bridges, C. R., Califf, R. M., Casey, D. E., Jr., Chavey, W. E., 2nd, Fesmire, F. M., Hochman, J. S., Levin, T. N., Lincoff, A. M., Peterson, E. D., Theroux, P., Wenger, N. K., Wright, R. S., Smith, S. C., Jr., Jacobs, A. K., Adams, C. D., Anderson, J. L., Antman, E. M., Halperin, J. L., Hunt, S. A., Krumholz, H. M., Kushner, F. G., Lytle, B. W., Nishimura, R., Ornato, J. P., Page, R. L., \& Riegel, B., American College of Cardiology, American Heart Association Task Force on Practice Guidelines (Writing Committee to Revise the 2002 Guidelines for the Management of Patients With Unstable Angina/Non-ST-Elevation Myocardial Infarction), American College of Emergency Physicians, Society for Cardiovascular Angiography and Interventions, Society of Thoracic Surgeons, American Association of Cardiovascular and Pulmonary Rehabilitation, \& Society for Academic Emergency Medicine (2007). ACC/AHA 2007 guidelines for the management of patients with unstable angina/non-ST-Elevation myocardial infarction: a report of the American College of Cardiology/American Heart Association Task Force on Practice Guidelines (Writing Committee to Revise the. Journal of the American College of Cardiology, 50(7), e1-e157. http://dx.doi.org/10.1016/j.jacc.2007.02.013. PMid:17692738.

Bang, C., Batkai, S., Dangwal, S., Gupta, S. K., Foinquinos, A., Holzmann, A., Just, A., Remke, J., Zimmer, K., Zeug, A., Ponimaskin, E., Schmiedl, A., Yin, X., Mayr, M., Halder, R., Fischer, A., Engelhardt, S., Wei, Y., Schober, A., Fiedler, J., \& Thum, T. (2014). Cardiac fibroblastderived microRNA passenger strand-enriched exosomes mediate cardiomyocyte hypertrophy. The Journal of Clinical Investigation, 124(5), 2136-2146. http://dx.doi.org/10.1172/JCI70577. PMid:24743145.

Bauernfeind, F., Rieger, A., Schildberg, F. A., Knolle, P. A., SchmidBurgk, J. L., \& Hornung, V. (2012). NLRP3 inflammasome activity is negatively controlled by miR-223. Journal of Immunology (Baltimore, Md.: 1950), 189(8), 4175-4181. http://dx.doi.org/10.4049/ jimmunol.1201516. PMid:22984082.

Boersma, E., Mercado, N., Poldermans, D., Gardien, M., Vos, J., \& Simoons, M. L. (2003). Acute myocardial infarction. Lancet, 361(9360), 847-858. http://dx.doi.org/10.1016/S0140-6736(03)12712-2. PMid:12642064.

Cook, R. J., Dickens, B. M., \& Fathalla, M. F. (2003). World Medical Association Declaration of Helsinki: Ethical Principles for Medical Research Involving Human Subjects. Ferney-Voltaire: WMA.

Feng, Z., Qi, S., Zhang, Y., Qi, Z., Yan, L., Zhou, J., He, F., Li, Q., Yang, Y., Chen, Q., Xiao, S., Li, Q., Chen, Y., \& Zhang, Y. (2017). Ly6G+ neutrophil-derived miR-223 inhibits the NLRP3 inflammasome in mitochondrial DAMP-induced acute lung injury. Cell Death \& Disease, 8(11), e3170. http://dx.doi.org/10.1038/cddis.2017.549. PMid:29144508.

Frangogiannis, N. G., Smith, C. W., \& Entman, M. L. (2002). The inflammatory response in myocardial infarction. Cardiovascular Research, 53(1), 31-47.http://dx.doi.org/10.1016/S0008-6363(01)004345. PMid:11744011.

Haneklaus, M., Gerlic, M., Kurowska-Stolarska, M., Rainey, A. A., Pich, D., McInnes, I. B., Hammerschmidt, W., O’Neill, L. A., \& Masters, S. L. (2012). Cutting edge: miR-223 and EBV miR-BART15 regulate the NLRP3 inflammasome and IL-1 $\beta$ production. Journal of Immunology (Baltimore, Md.: 1950), 189(8), 3795-3799. http://dx.doi.org/10.4049/ jimmunol.1200312. PMid:22984081. 
Haneklaus, M., Gerlic, M., O’Neill, L. A. J., \& Masters, S. L. (2013). miR-223: infection, inflammation and cancer. Journal of Internal Medicine, 274(3), 215-226. http://dx.doi.org/10.1111/joim.12099. PMid:23772809.

Hartman, M. H. T., Groot, H. E., Leach, I. M., Karper, J. C., \& Harst, P. V. D. (2018). Translational overview of cytokine inhibition in acute myocardial infarction and chronic heart failure. Trends in Cardiovascular Medicine, 28(6), 369-379. http://dx.doi.org/10.1016/j. tcm.2018.02.003. PMid:29519701.

Hristov, M., \& Weber, C. (2015). Myocardial infarction and inflammation: lost in the biomarker labyrinth. Circulation Research, 116(5), 781-783. http://dx.doi.org/10.1161/CIRCRESAHA.115.305919. PMid:25722440.

Liu, X., Zhang, Y., Du, W., Liang, H., He, H., Zhang, L., Pan, Z., Li, X., Xu, C., Zhou, Y., Wang, L., Qian, M., Liu, T., Yin, H., Lu, Y., Yang, B., \& Shan, H. (2016). MiR-223-3p as a Novel MicroRNA Regulator of Expression of Voltage-Gated K+ Channel Kv4.2 in Acute Myocardial Infarction. Cellular Physiology and Biochemistry, 39(1), 102-114. http://dx.doi.org/10.1159/000445609. PMid:27322747.

Liu, Y., Lian, K., Zhang, L., Wang, R., Yi, F., Gao, C., Xin, C., Zhu, D., Li, Y., Yan, W., Xiong, L., Gao, E., Wang, H., \& Tao, L. (2014). TXNIP mediates NLRP3 inflammasome activation in cardiac microvascular endothelial cells as a novel mechanism in myocardial ischemia/ reperfusion injury. Basic Research in Cardiology, 109(5), 415. http:// dx.doi.org/10.1007/s00395-014-0415-z. PMid:25015733.

Lu, H., Buchan, R. J., \& Cook, S. A. (2010). MicroRNA-223 regulates Glut4 expression and cardiomyocyte glucose metabolism. Cardiovascular Research, 86(3), 410-420. http://dx.doi.org/10.1093/cvr/cvq010. PMid:20080987.

Maier, W., Altwegg, L. A., Corti, R., Gay, S., Hersberger, M., Maly, F. E., Sütsch, G., Roffi, M., Neidhart, M., Eberli, F. R., Tanner, F. C., Gobbi, S., von Eckardstein, A., \& Lüscher, T. F. (2005). Inflammatory markers at the site of ruptured plaque in acute myocardial infarction: locally increased interleukin- 6 and serum amyloid A but decreased C-reactive protein. Circulation, 111(11), 1355-1361. http://dx.doi.org/10.1161/01.CIR.0000158479.58589.0A. PMid:15753219.

Mendis, S., Thygesen, K., Kuulasmaa, K., Giampaoli, S., Mähönen, M., Ngu Blackett, K., \& Lisheng, L., \& Writing group on behalf of the participating experts of the WHO consultation for revision of WHO definition of myocardial infarction (2011). World Health Organization definition of myocardial infarction: 2008-09 revision. International Journal of Epidemiology, 40(1), 139-146. http://dx.doi. org/10.1093/ije/dyq165. PMid:20926369.

Mezzaroma, E., Toldo, S., Farkas, D., Seropian, I. M., Van Tassell, B. W., Salloum, F. N., Kannan, H. R., Menna, A. C., Voelkel, N. F., \& Abbate, A. (2011). The inflammasome promotes adverse cardiac remodeling following acute myocardial infarction in the mouse. Proceedings of the National Academy of Sciences of the United States of America, 108(49), 19725-19730. http://dx.doi.org/10.1073/pnas.1108586108. PMid:22106299.

Michaels, A. D., Gibson, C. M., \& Barron, H. V. (2000). Microvascular dysfunction in acute myocardial infarction: focus on the roles of platelet and inflammatory mediators in the no-reflow phenomenon. The American Journal of Cardiology, 85(5A), 50B-60B. http://dx.doi. org/10.1016/S0002-9149(00)00811-0. PMid:11076131.

Mishra, B. B., Rathinam, V. A., Martens, G. W., Martinot, A. J., Kornfeld, H., Fitzgerald, K. A., \& Sassetti, C. M. (2013). Nitric oxide controls the immunopathology of tuberculosis by inhibiting NLRP3 inflammasome-dependent processing of IL-1 $\beta$. Nature Immunology, 14(1), 52-60. http://dx.doi.org/10.1038/ni.2474. PMid:23160153.
Mulay, S. R., Kulkarni, O. P., Rupanagudi, K. V., Migliorini, A., Darisipudi, M. N., Vilaysane, A., Muruve, D., Shi, Y., Munro, F., Liapis, H., \& Anders, H. J. (2013). Calcium oxalate crystals induce renal inflammation by NLRP3-mediated IL- $1 \beta$ secretion. The Journal of Clinical Investigation, 123(1), 236-246. http://dx.doi.org/10.1172/ JCI63679. PMid:23221343.

Neudecker, V., Haneklaus, M., Jensen, O., Khailova, L., Masterson, J. C., Tye, H., Biette, K., Jedlicka, P., Brodsky, K. S., Gerich, M. E., Mack, M., Robertson, A. A. B., Cooper, M. A., Furuta, G. T., Dinarello, C. A., O’Neill, L. A., Eltzschig, H. K., Masters, S. L., \& McNamee, E. N. (2017). Myeloid-derived miR-223 regulates intestinal inflammation via repression of the NLRP3 inflammasome. The Journal of Experimental Medicine, 214(6), 1737-1752. http://dx.doi. org/10.1084/jem.20160462. PMid:28487310.

Ong, S. B., Hernández-Reséndiz, S., Crespo-Avilan, G. E., Mukhametshina, R. T., Kwek, X. Y., Cabrera-Fuentes, H. A., \& Hausenloy, D. J. (2018). Inflammation following acute myocardial infarction: multiple players, dynamic roles, and novel therapeutic opportunities. Pharmacology \& Therapeutics, 186, 73-87. http://dx.doi.org/10.1016/j. pharmthera.2018.01.001. PMid:29330085.

Pop, M., Qi, X., Barry, J., Strauss, B. H., Wright, G. A., \& Ghugre, N. R. (2014). Hemorrhage promotes inflammation and myocardial damage following acute myocardial infarction. Journal of Cardiovascular Magnetic Resonance, 16(S1), 1-2. http://dx.doi.org/10.1186/1532429X-16-S1-O72.

Reed, G. W., Rossi, J. E., \& Cannon, C. P. (2017). Acute myocardial infarction. Lancet, 389(10065), 197-210. http://dx.doi.org/10.1016/ S0140-6736(16)30677-8. PMid:27502078.

Schroder, K., Zhou, R., \& Tschopp, J. (2010). The NLRP3 inflammasome: a sensor for metabolic danger? Science, 327(5963), 296-300. http:// dx.doi.org/10.1126/science.1184003. PMid:20075245.

Wang, G. K., Zhu, J. Q., Zhang, J. T., Li, Q., Li, Y., He, J., Qin, Y. W., \& Jing, Q. (2010). Circulating microRNA: a novel potential biomarker for early diagnosis of acute myocardial infarction in humans. European Heart Journal, 31(6), 659-666. http://dx.doi.org/10.1093/eurheartj/ ehq013. PMid:20159880.

Westman, P. C., Lipinski, M. J., Luger, D., Waksman, R., Bonow, R. O., Wu, E., \& Epstein, S. E. (2016). Inflammation as a Driver of Adverse Left Ventricular Remodeling After Acute Myocardial Infarction. Journal of the American College of Cardiology, 67(17), 2050-2060. http://dx.doi.org/10.1016/j.jacc.2016.01.073. PMid:27126533.

Yang, L., Fan, H., Liu, Z., \& Zhan, Z. (2015a). GW26-e4725 microRNA-21 regulates post-ischemic inflammation triggered by DAMPs in myocardial infarction through targeting STK40. Journal of the American College of Cardiology, 66(16), C25-C25. http://dx.doi. org/10.1016/j.jacc.2015.06.1124.

Yang, S., Fu, C., Xu, R., Xun, Z., Zhao, X., \& Fang, R. (2017). Serum microRNA-302b: the novel biomarker for diagnosis of acute myocardial infarction. British Journal of Biomedical Science, 74(4), 214-216. http://dx.doi.org/10.1080/09674845.2017.1333665. PMid:28752786.

Yang, Z., Zhong, L., Xian, R., \& Yuan, B. (2015b). MicroRNA-223 regulates inflammation and brain injury via feedback to NLRP3 inflammasome after intracerebral hemorrhage. Molecular Immunology, 65(2), 267-276. http://dx.doi.org/10.1016/j.molimm.2014.12.018. PMid:25710917.

Zhou, R., Yazdi, A. S., Menu, P., \& Tschopp, J. (2011). A role for mitochondria in NLRP3 inflammasome activation. Nature, 469(7329), 221-225. http://dx.doi.org/10.1038/nature09663. PMid:21124315.

Zhuang, G., Meng, C., Guo, X., Cheruku, P. S., Shi, L., Xu, H., Li, H., Wang, G., Evans, A. R., Safe, S., Wu, C., \& Zhou, B. (2012). A novel regulator of macrophage activation: $\mathrm{miR}-223$ in obesity-associated adipose tissue inflammation. Circulation, 125(23), 2892-2903. http:// dx.doi.org/10.1161/CIRCULATIONAHA.111.087817. PMid:22580331. 